\title{
Review of Strategic Planning Model in Higher Education: The OMC Model
}

\author{
Mubarak Pasha $^{1} \&$ Mullaicharam Bhupathyraaj ${ }^{1}$ \\ ${ }^{1}$ Oman Medical College, Oman \\ Correspondence: Mubarak Pasha, Oman Medical College, Oman.
}

Received: June 10, 2018

Accepted: June 24, 2018

Online Published: June 27, 2018

doi:10.5430/ijba.v9n4p45

URL: https://doi.org/10.5430/ijba.v9n4p45

\begin{abstract}
The concept of strategic planning has extensively been used to formulate institutional objectives of higher education institutions into time bound deliverables. Although there is a general agreement on the conceptual note on the strategic planning process, the differences are conspicuous in its internal process of transformation from strategic formulation to implementation. Consequently, models that apply to higher education institutions have been drawn up in the management sciences in the last quarter of the twentieth century. However, the format for institutional review of strategic planning is still in its infancy although its review constitutes a conspicuous phase of institutional planning. The foregoing discussion is intended to prescribe a general format for an institutional review of a strategic planning model. It runs on the hypothesis that the review has three phases, though not mutually exclusive, viz. review of the framework, review of the process, and review of the outcome. The paper under discussion is an attempt to develop a new logical framework for the review of the strategic plan of an educational institution. The model is labelled as the OMC model as it was developed for and subsequently used in Oman Medical College.
\end{abstract}

Keywords: strategic planning, institutional review, operational zone, silent zone, propensity of deployment, measure of completion

\section{Introduction}

'As the twentieth century draws to close and the twenty first century dawns before us, those of us who have dedicated our careers to the pursuit of academic excellence in the classrooms and laboratories of America's colleges and Universities find that the massive changes that are occurring in the world around us are intruding into the academic realm as well' (Rowley, DJ., Lujan, HD., Dolence, MG, 1995). 'In agreement with Smith's suggestion that education generally is disorganized and disorderly, unplanned, and dysfunctional' (Smith, F, 1994) many have proposed a drastic restructuring of the higher education institutional framework and method that has resulted in a breakthrough in its management. Compounded with the pressure of a market based commodity culture, the higher education sector underwent significant structural changes in its form and content. The application of management process into higher education was one of the striking features of this new transformation and obviously an extension of the strategic planning concept and practices for sustainable development conspicuously figures in the new environment.

The concept of strategic planning has extensively been used over the globe to formulate institutional objectives into time bound deliverables. However, 'there is a general misconception of what strategic planning is and what it is not' (Mintzberg, H, 1994). Apparently, misconceptions are more or less a miscomprehension of its dynamics in the context of non-profit institutions. The commonsense view of Strategic Planning is well explained in the definition of Cyert that runs as 'the objective of strategic planning is to establish a plan by which a department, college or university can achieve a position that gives it a special place among other departments, colleges or universities' (Cyert, RM, 1988). In theory and practice, 'Strategic Planning seeks to align the organization with the environment in order to help assure long-term stability and survival' (Gilbert, JT, 1993). Following the jargons of strategic planning process of a typical commercial initiative, the framework of the higher education strategic planning deploys almost similar methodologies in strategic formulation and strategic implementation. The methodology remains the same at least in shaping the strategic plan models and the thread connecting the institutional vision to its strategic objectives passes through identical domains of goal setting, environmental scan, and formulating achievable target. Practically, every educational provider gets transformed into a point of production of a well-defined commodity, 
known as programs or courses and its students are considered to be the final customers of an organized process. It keeps every educational provider in a space of stiff competition with other educational providers so much so that everyone deploys strategies to reap advantages over others through quality deliverables. It requires them to plan its short-term and long-term goals in tune with the institutional priorities for which they have no other choice than to develop a strategic plan as its future directive. Therefore, regardless of their institutional gradation all higher education providers deploys a formatted plan model as a mandatory condition of institutional survivability.

Being integrated into a timeline, the strategic plan model is bound to have a termly assessment and review. By definition and practice, the review starts from the day of its implementation although most of the institutions deploy annual stock taking as an institutional introspection. Finally, a detailed review exercise with a measurable assessment is drawn up on expiry of the plan period. No institution can move forward without a rigorous introspection on the effectiveness of the plan model and it is an inherent virtue of a strategic planning exercise regardless of the institutional profile, profit or non-profit organization.

\section{General Framework of a Strategic Plan Model}

Although there is a general agreement on the conceptual note on the strategic planning process, the differences are conspicuous in its internal process of transformation from strategic formulation to implementation. It makes the content of the strategic plan process quite specific to the institutional climate and approach. 'Models that apply to higher education have been developed by many in the last decade of twentieth century and the one drawn up by Bryson for strategic planning in public and non-profit organizations is considered to be the proto model' (Bryson, JM, 1989). Subsequently, there has been a phenomenal growth in developing a framework for Strategic Planning exercise for educational institution. The following figure no. 1 describes the flow of the process which is used in foregoing discussions as the base model without prejudice to the right to deploy any nomenclature and retaining strict adherence to the linearity of mapping.

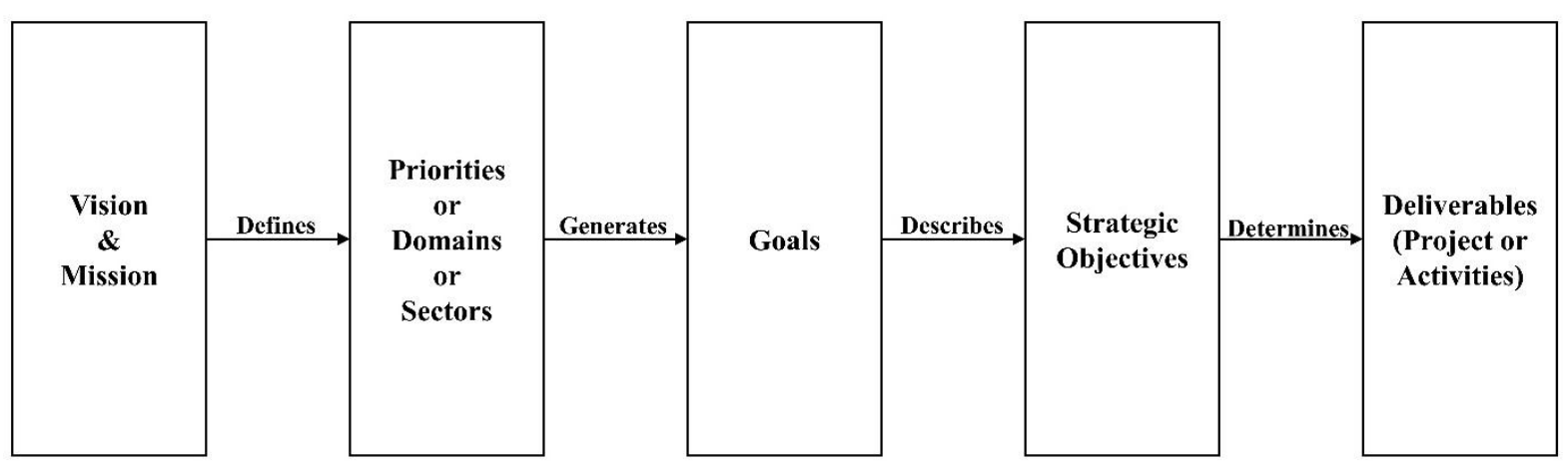

Figure 1. Flow of planning process

\subsection{Postulates}

Vision and Mission identifies a set of finite priority or sector or domain

Each priority spans a set of unique and finite goals

Each goal has its own unique and finite strategic objectives

Each strategic objective elucidate visible/tangible deliverables in the form of project and activity

\section{Review of the Strategic Plan: The OMC Model}

No matter how the Strategic Plan is defined, it has an inherent destination: realization of its intuitional goals through a structured plan of actions involving physical and human resources. Therefore, the review of the Strategic Plan stands as conspicuous as the process leading to model building. The latter is a reflection on the institutional objectives for deducing it into visible deliverables and it remains as a customized package for deployment of its resources during a definite period of time. The former on the other hand looks at institutional dreams but with a different yardstick to discern effectiveness as well as accomplishment. The foregoing discussion is intended to prescribe a general format for an institutional review of a strategic planning model. As the framework was developed 
to review the Oman Medical College's strategic plan for the years 2013-18, it is to be known as the OMC model for strategic plan review.

Notwithstanding the operational differences between a business organization and educational institution in terms of its form and content, the format for the review of strategic plan is sourced from the same conceptual framework. It broadly falls under three headings, review of the framework, review of the process, and review of the outcome. These three phases, though not mutually exclusive, portray distinct premises of comprehension and analysis. The first and the second are common to all types of institutions including no profit organizations whereas the third phase has added significance in the educational sector as the line of demarcation between output and outcome seldom occurs in the normal business model. As a logical derivative, this model has a dual destination viz. to measure the degree of realization of the strategic objectives (Operational Zone), and identify the segments that appear not to be functional at all (Silent Zone) in addition to its ultimate goal of discerning the impact on the macro indicators of the institution.

\subsection{Review of the Framework}

The review of the Strategic Plan is the building block for the succeeding plan model and therefore, the review of the framework of the SP model stands as the starting point of evaluation. By definition, the strategic plan model is bound to have a prescription that can define expected area of operations during the period of the plan. As discussed elsewhere, the Strategic Plan derives its reason from the vision and the mission of the higher education institution and is in agreement with the general pattern of evolving a planning process. The mapping from the vision and mission to the goals and then to the strategic objectives is governed by a linearity of relationship and therefore, the review passes through the same pathway but in reverse order. The Strategic Plan model is similar to a pyramid with a wide base denoting more specific strategic objectives and it allows a discrete functional relationship among the strategic objectives to its corresponding goals.

$$
z=f(x) \rightarrow g(y) \text { where } z=\text { Strategic Plan, } x=\text { Goals, and } y=\text { Strategic Objectives }
$$

It generates a two dimensional vector space where each and every point has a unique combination of well-defined goals and their strategic objectives. However, the mapping of strategic objectives into output need not follow the above equation as each and every strategic objective can have more than one output. The following figure describes the mapping.

$$
\begin{aligned}
& \left(n_{i 1} n_{i 2} n_{i 3} \ldots \ldots \ldots n_{i n}\right) \\
& \rightarrow y, \text { where } y_{i} \text { denotes a specific strategic objective and } n_{i 1} \text { denotes a specific deliverable output } \\
& \text { in the form of activty or project. }
\end{aligned}
$$

It allows us to relate more than one output to one and only one strategic objective. Therefore, the review process follows a mapping in reverse order which is shown in the following Figure 2.

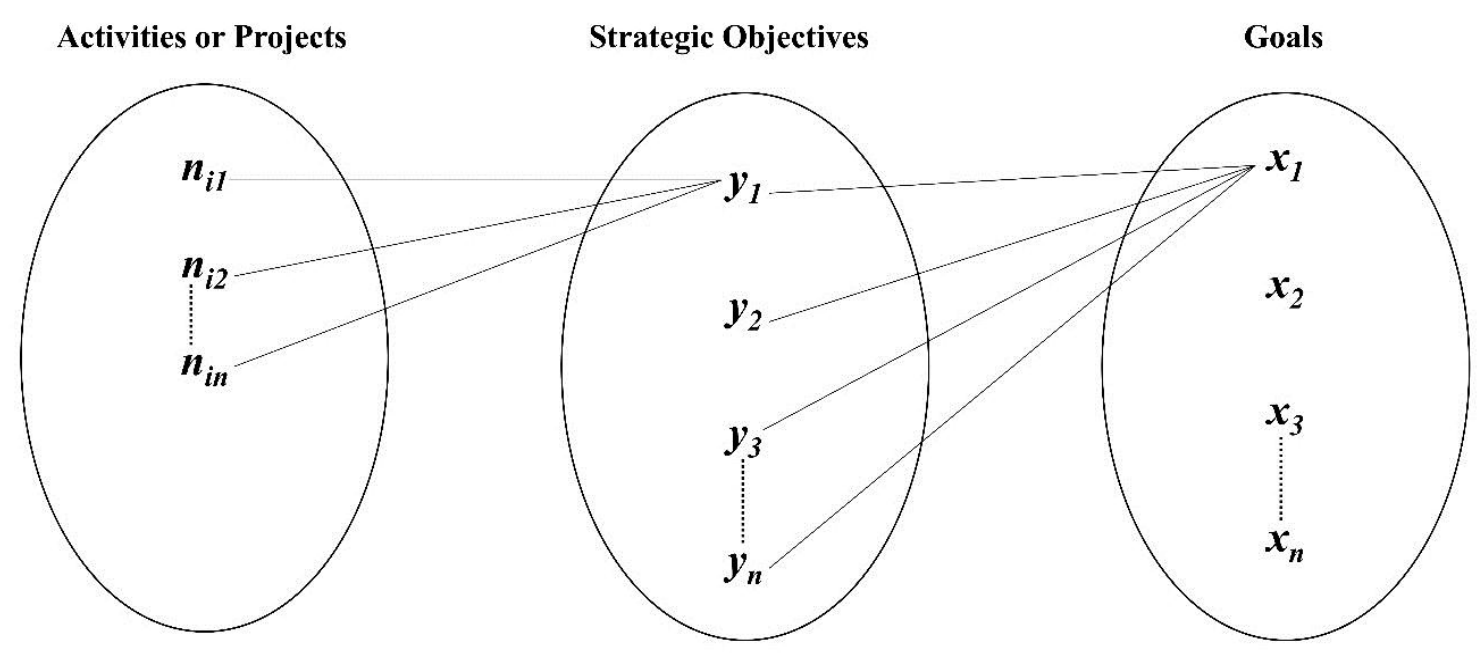

Figure 2. Mapping in reverse order 
The review accordingly provides two categories of environment depending on the responsiveness of the institution viz. operational zone and silent zone.

\subsubsection{Operational Zone}

It is characterized by the output although it can have completion at different levels. In other words it suggests the zone where the institution has affirmative actions to address the strategic objectives.

\subsubsection{Silent Zone}

The silent zone depicts non-responsiveness of the institution. It can happen due to either the absence of a prescription or withdrawal from the approved item. The silent zone is a critical component of the review process as it gives directives to the institution to revisit its form and content for either special consideration or deletion as the case may be in the succeeding plan model.

The review of the framework has a flexible format with a view to suit itself to the varying identities of the strategic plan and therefore it is imperative to look at the framework from all possible points of assessment. It can lead to the deletion of an already approved prescription or propose relocation of the strategic objectives in order to portray reasonable sync with the goals. In short, the review of the framework looks at macro identities of the plan model through an internal scan of its functional and operational linkages across the plan phases.

\subsection{Review of the Process}

Despite the qualitative differences in the conceptualization of the plan models between the business and educational organizations there is a conceptual convergence to the deployment of a tangible processes leading to deliverables. The Strategic Objectives are instructional in providing clues to higher education institutions to design an appropriate scheme of action which is reflected normally in the operational plan or annual plan as the case may be. However, the higher education institution has inherent restrictions in terms of the combinations of an action plan to realize its goals. The most convenient forms of collective action for output are classified as projects and activities and therefore each strategic objective can have its own projects and/or activities in order to achieve its strategic objectives. It allows the review to start from project and/or activities for an appropriate assessment against the expected outcome as defined in the plan document. Every project and activity is subject to an overall evaluation using permissible and appropriate indicators of success. It has two levels (i) Propensity of Deployment and (ii) Measure of Completion. Both of these levels are simply numerical values that can be represented as ratio.

\subsubsection{Level 1-Propensity of Deployment}

Degree of responsiveness of the HEI to strategic objectives known as propensity of a deployment of resources. It is one of the critical aspect of the institutional review of the Strategic Plan. It is mandatory as well as customary for an institution to understand as to how it responded to its well-defined strategic objectives through an approved action plan for output. It is a measure of propensity of deployment and by definition is different and distinct from the measure of success.

$$
k(\text { Propensity of Deployment })=\frac{\sum x_{i}}{\sum y_{i}}
$$

Where $x_{i}$ represents project/activity proposed for $i$ th strategic objectives and $y_{i}$ represents $i$ th strategic objectives drawn up in the approved strategic plan for each sector or priority or domain as the case may be.

Necessary and sufficient condition: $x_{i}=0$ or 1

Therefore, $0 \leq k \leq 1$

\subsubsection{Level 2-Measure of Completion}

Conceptually different from the measure of propensity of deployment, the measure of completion refers to the degree of effective completion of the approved projects and activities. It is a numerical value independent of units.

$$
p(\text { Measure of Completion })=\frac{\sum x_{p}}{\sum y_{p}}
$$

Where $x_{p}$ represents $p$ th strategic objectives that have been effectively completed project/activity and $y_{p}$ represents $p$ th strategic objectives that have approved projects/activities per priority or domain or sector as the case may be. Therefore, $0 \leq p \leq 1$ and $p=k=1$ implies a perfect pathway with zero silent zone denoting a successful strategic plan implementation. 


\subsubsection{Corollary 1}

The above equation allows us to presume that operational zone moves within a range of 0 to 1 . When it takes the value of 1 it denotes an exhaustive operational zone.

\subsubsection{Corollary 2}

Similarly, the silent zone moves within a range of 0 to 1 . When it takes the value of 1 it denotes an exhaustive silent zone.

\subsection{Review of Outcome}

Review of outcome is a comprehensive analysis of the impact reflected on the macro indicators of the institution. Technically, it is a qualitative mapping of the output generated through the strategic plan implementation and therefore it requires a logical deduction of multiple factors resulting in a visible realization of the variables of institutional growth.

\subsubsection{Step 1: Deploy an Internal Environmental Scan}

A thorough analysis through an internal environmental scan of the institutional macro indicators is to be conducted to discern cumulative growth caused through the strategic plan under the review $\left(\mathrm{A}_{1}\right)$.

\subsubsection{Step 2: Comparison}

A qualitative analysis through a comparison with the environmental scan summary of the preceding period $\left(\mathrm{A}_{2}\right)$ is to be deployed. The resultant difference between $\left(A_{1}\right)$ and $\left(A_{2}\right)$ gives the review of the outcome of the process as detailed in the framework of a strategic plan during a period of time.

It implies that $\mathrm{A}_{1}>\mathrm{A}_{2}$ for most of the macro indicators denoting a linearity of growth.

\section{Conclusion}

The model has been used as a review instrument for the Strategic Plan of Oman Medical College for the years 2013-18 and has been instrumental in bringing out conspicuous observations and findings pertaining to the strategic formulation and implementation. The model is noted on testing for its inherent possibilities to discern micro level attributes.

\section{References}

Bryson, J.M. (1989). Strategic Planning for Public and Non-profit Organizations: A Guide to Strengthening and Sustaining Organizational Achievement. Jossey-Bass, San Francisco.

Cyert, R.M. (1988). Carnegie Mellon University. In D.W. Steeples (Ed.), Successful Strategic Planning: Case Studies. New Directions for Higher Education (p. 64). Jossey-Bass, San Francisco. https://doi.org/10.1002/he.36919886411

Gilbert, J.T. (1993). Faster! Newer! Is not a Strategy. SAM Advanced Management Journal, 4-8.

Mintzberg, H. (1994). The Rise and Fall of Strategic planning. Free Press, New York.

Rowley, D.J., Lujan, H.D., \& Dolence, M.G. (1997). Strategic Change in Colleges and Universities: Planning to Survive and Prosper. Jossey Bass, San Francisco.

Smith, F. (1995). Let's Declare Education a Disaster and Get in with Our Lives. The Phi Delta Kappan. (Phi Delta Kappa International, Bloomington), 584-590. 